Bidang ilmu: Keperawatan

\title{
PEMBERIAN TABLET ZINC DENGAN DURASI DIARE PADA BALITA
}

\author{
Yuniar Kusumawardani1), Rokhaidah2) \\ Fakultas Ilmu Kesehatan1,2) \\ Universitas Pembangunan Nasional Veteran Jakarta \\ yuniarkusumawardani@upnvj.ac.id1); rokhaidah@upnvj.ac.id²)
}

\begin{abstract}
ABSTRAK
Latar belakang : Di Indonesia diare masih merupakan penyebab kematian balita di setiap harinya. Pemerintah merekomendasikan penanganan diare salah satunya pemberian tablet zinc. Manfaat zinc dapat membantu proses perbaikan fungsi vili dalam penyerapan makanan. Tujuan : dari penelitian ini untuk menganalisis pemberian tablet zinc dengan durasi diare pada balita. Metode : Desain penelitian ini menggunakan Cross Sectional. Teknik yang digunakan dalam pengambilan sampel yaitu accidental sampling dengan sampel 75 balita. Pengambilan data dilakukan dengan kuesioner yang disebarkan secara online menggunakan bantuan aplikasi google form. Penelitian ini menggunakan metode Uji Kolerasi Rank Spearman. Hasil : dari 75 responden rata-rata pemberikan tablet zinc selama 6 hari dan dari 75 responden rata-rata durasi diare pada balita selama 3 hari. Kesimpulan : ada hubungan pemberian tablet zinc dengan durasi diare pada balita dengan $p$ value (0.027). Rekomendasi : Penelitian ini disarankan lebih untuk melakukan pendampingan dalam pemberian tablet zinc agar lebih patuh dan dapat memperkuat hasil penelitian.
\end{abstract}

Kata Kunci : Zinc, durasi diare, dan balita

\begin{abstract}
Background : In Indonesia, diarrhea is still the cause of infant mortality. Government Tablet. The benefits of zinc can help the process of improvement in pushing food. Objective : from this study to analyze zinc tablets with the duration of diarrhea in infants. Method : Disable this research using Cross-Sectional. The technique used in taking the sample is accidental sampling with a sample of 75 toddlers. Data is collected by a questionnaire distributed online using the help of Google forms. This study uses the Rank Spearman correlation test. Results : From 75 respondents the average delivery of zinc tablets for 6 days and from 75 respondents the average duration of diarrhea in children for 3 days. Conclusion : there was a contribution of zinc tablets with a duration of diarrhea in infants with $p$ values (0.027). Recommendation : This research suggests more assistance in giving zinc tablets to be more compliant and can support research results.
\end{abstract}

Key Words: Zinc; duration of diarrhea and toddler

Alamat korespondensi: Jakarta

Email: yuniarkusumawardani@upnvj.ac.id

Nomor Hp: 08559884186 


\section{PENDAHULUAN}

Menurut World Health Organization (WHO) kesehatan merupakan suatu keadaan sehat, baik keadaan fisik, mental maupun keadaan sosial. Berdasarkan hasil survei sosial ekonomi nasional (Susenas) 2017 didapatkan anak yang miliki keluhan kesehatan sebanyak 28,56\%, dan angka kesakitan anak usia 0-17 tahun sebesar 15,86\% (kementrian pemberdayaan perempuan dan perlindungan anak, 2018). Tingginya angka mortalitas dan morbiditas di Indonesia yang sering menimbulkan kejadian luar biasa disebabkan oleh diare sekitar 20\% infeksi diare menimbulkan meninggal dunia (Huda, Perwitasari, \& Risdiana, 2017).

Menurut World Health Organization (WHO) Diare adalah keluarnya feses cair dengan frekuensi lebih dari 3 kali 24 jam, diare akut dapat terjadi selama 3 sampai 7 hari bahkan bisa sampai 14 hari. Gejala ini merupakan suatu gejala infeksi gastrointestinal yang disebabkan oleh masuknya mikroorganisme melalui makanan dan minuman yang terkontaminasi atau dikarenakan akibat dari kebersihan yang kurang baik. Patogen vibrio cholera, Escherichia coli, dan rotavirus yaitu penyebab umumnya terjadi diare (Riskiyah, 2017). Diare disebabkan karena adanya gerakan peningkatan peristaltik usus yang isinya akan terdorong ke saluran akhir yaitu rektum sehingga dapat memicu untuk buang air besar (Wijayanti \& Astuti, 2019). Faktor yang dapat menyebabkan diare akut pada anak usia 1-5 tahun yaitu kurangnya berat badan lahir tidak dalam batas normal, imunisasi tidak lengkap, status gizi pada anak, terdapat riwayat pemberian tablet zinc, tingkat pengetahuan ibu, ASI tidak eksklusif, personal hygiene ibu (Akbar, 2017). Selain perilaku kebersihan, keadaan lingkungan, dan sanitasi yang baik itu saja tidak cukup dalam menangani kejadian diare jika tidak didampingi dengan perilaku kepatuhan pemberian obat diare (Pujianti, 2018).

Pada cakupan Asia Tenggara (ASEAN) Indonesia menempati urutan ke 6 kematian balita akibat dari diare (Latif, 2015). Berdasarkan data Nasional Indonesia sebagai negara berkembang sekitar 273 balita setiap harinya meninggal dunia disebabkan oleh penyakit infeksi diare. Dengan demikian penyakit ini menunjukkan bahwa penderita diare terbesar pada usia 6 bulan sampai 5 tahun yaitu $50.51 \%$ penderita penyakit infeksi diare. Penyebab utama kematian anak dengan prevalensi tertinggi (Kemenkes RI, 2011). Laporan Riset Kesehatan Dasar (Riskesdas) tahun 2018 di Indonesia angka kejadian diare sebesar $6,8 \%$, pada balita didapatkan peningkatan yang signifikan ditahun 2018 sebesar 11,0\% dari tahun 2013 sebesar 2,4\% (Kemenkes RI, 2018). Data yang diperoleh Provinsi Jawa Barat pada tahun 2018 termasuk dalam 10 besar penyakit diare tertinggi yaitu sekitar $7,0 \%$ penderita, balita yang terdiagnosis penyakit diare di jawa barat juga menepati urutan 10 besar tertinggi yaitu sekitar 13,1\%. Berdasarkan Lembaga Biblika Indonesia Sistem Informasi Manajemen Puskesmas (LBI SIMPUS) 2018 Jumlah penyakit rawat jalan di puskesmas kota depok diare pada usia 1-4 tahun menempati urutan ke 5 yaitu 7,97\% posisi pertama masih ditempati oleh penyakit infeksi saluran pernapasan atas dan nasofaringitis akut sebanyak 28,04\% (Dinas Kesehatan Kota Depok, 2019).

Diare mengakibatkan munculnya gejala ketidaknyamanan yaitu panas tubuh, nyeri perut, nafsu makan yang menurun, kelelahan, berat badan menjadi turun serta kehilangan cairan elektrolit yang signifikan. Komplikasi yang muncul akibat penyakit diare juga tidak ditangani dengan tepat akan muncul penyakit penyakit baru seperti dehidrasi, syok hipovolemik, kerusakan pada organ hingga dapat terjadi kematian (Anitasari \& Sappe, 2019). Bahaya jika diare tidak teratasi akan minumbulkan kurangnya cairan elektrolit dan tubuh tidak mendapatkan asupan gizi yang cukup dikarenakan cairan dalam tubuh yang hilang (Restuti \& Fitri, 2019).

Terdapat hubungan erat kejadian diare dengan asupan zat gizi mikro pada balita yang berfungsi sebagai sistem pertahanan tubuh yaitu mineral dan vitamin. Balita memerlukan zat gizi mikro yang berfungsi sebagai sistem pertahanan tubuh pada saluran pencernaannya seperti suplemen zinc, vitamin A, polyunsaturated fatty acid (PUFA) (Restuti \& Fitri, 2019). Penanganan buang air besar dapat diberikan kepada penderita diare dengan intervensi pemberian oralit, tablet zinc, ASI/makanan yang cukup, obat antibiotic, dan memberikan edukasi kepada keluarga balita (Wijayanti \& Astuti, 2019). 
Zinc dapat bekerja sebagai mencegah bakteri yang masuk ke saluran gastrointestinal, dapat memperbaiki fungsi villi dan usus dapat bergenerasi secara cepat (Restuti \& Fitri, 2019). Zinc penting dalam sistem imun serta sebagai sistem pertahanan infeksi dan dapat minimalisir keparahan risiko (Wahyuni \& Dermawan, 2018). Oralit dan zinc dapat digunakan sebagai penanganan pertama pada balita untuk mengurangi durasi diare dengan pemberian selama 10-14 hari (Illahi, P, \& Sadharta, 2016). Zinc dapat diberikan setiap hari selama 10 hari untuk usia balita > 6 bulan diberikan 1 tablet dan balita $<6$ bulan diberikan $1 / 2$ tablet, tablet zinc ini penggunaannya dengan cara dilarutkan dalam 1 sendok air (Indriani, Fitriyanti, \& Azzikri, 2019).

Berdasarkan hasil data catatan pengunjung UPT Puskesmas Cinere Kota Depok pada bulan januari 2020 didapatkan terdapat 31 balita penderita diare. Staf Puskesmas juga mengatakan bahwa jika balita yang berkunjung karena diare akan diberikan intervensi pemberian terapi tablet zinc untuk 10 hari. Berdasarkan hasil pendahuluan yang dilakukan peneliti pada ibu yang memiliki anak balita 6 dari 10 ibu pernah mengalami anaknya diare. Hasil wawancara dari semua ibu didapatkan bahwa jika anaknya diare mereka akan berkunjung ke pelayanan kesehatan dan mendapatkan terapi tablet zinc, tetapi hanya diberikan selama 2-5 hari saja dikarenakan durasi diare pada anak sudah berkurang dan berhenti. Dari kondisi tersebut peneliti memili tujuan yaitu ingin menganalisis hubungan pemberian tablet zinc dengan durasi diare pada balita di Wilayah UPT Puskesmas Cinere Kota Depok.

\section{METODE PENELITIAN}

Metode penelitian ini menggunakan cross-sectional dengan penelitian kuantitatif menggunakan uji kolerasi Rank Spearman. Penelitian ini dilakukan di Wilayah UPT Puskesmas Cinere Kota Depok. Waktu penelitian dilakukan mulai dari bulan awal juni sampai pertengahan Juni 2020. Pengambilan sampel dilakukan dengan metode accidental sampling dengan jumlah 75 responden yang memiliki kriteria sebagai berikut : balita penderita diare akut dalam 3 bulan terakhir, balita usia 12-59 bulan, balita yang pernah berobat ke pelayanan kesehatan serta mendapatkan obat tablet zinc dari petugas kesehatan, dan memiliki akses smartphone untuk mengisi kuesioner online. Pengambilan data dilakukan dengan kuesioner melalui form online.

\section{HASIL DAN PEMBAHASAN}

Analisa Univariat

Tabel 1 Distribusi Rata-rata Usia Balita di Wilayah UPT Puskesmas Cinere Kota Depok (n=75).

\begin{tabular}{lcccc}
\hline Karakteristik & Mean & SD & SE & Min \\
\hline $\begin{array}{l}\text { Usia Balita } \\
\text { (bulan) }\end{array}$ & 22.51 & 7.216 & 0.833 & 13 \\
\hline
\end{tabular}

Sumber : Data peneliti 2020

Tabel 1 di atas menunjukkan distribusi rata-rata usia balita dari 75 responden yang diteliti adalah 22.51 bulan yang digenapkan menjadi 33 bulan. Usia termuda pada penelitian ini yaitu usia balita 13 bulan dan usia tertua yaitu usia balita 48 bulan.

Tabel 2 Distribusi Frekuensi Jenis Kelamin di Wilayah UPT Puskesmas Cinere Kota Depok $(n=75)$

\begin{tabular}{ccc}
\hline $\begin{array}{c}\text { Jenis } \\
\text { Kelamin }\end{array}$ & Frekuensi (n) & Persentase (\%) \\
\hline Laki-laki & 44 & $58.7 \%$ \\
\hline Perempuan & 31 & $41.3 \%$ \\
\hline Total & 75 & $100 \%$ \\
\hline
\end{tabular}

Sumber : Data Peneliti 2020 
Tabel 2 diatas, menunjukkan bahwa balita diare yang terlibat dalam penelitian ini sebagian besar berjenis kelamin laki-laki yaitu sebanyak $58.7 \%$ sedangkan pada balita diare berjenis kelamin perempuan sebanyak $41.3 \%$.

Tabel 3 Distribusi Rata-rata Pemberian Tablet Zinc di Wilayah UPT Puskesmas Cinere Kota Depok $(n=75)$

\begin{tabular}{lcccc}
\hline Variabel & Mean & SD & Min & Max \\
\hline $\begin{array}{l}\text { Pemberian } \\
\text { Tablet }\end{array}$ & 6.17 & 3.41 & 1 & 10 \\
Zinc & & & & \\
\hline Sumber : Data peneliti 2020 & & &
\end{tabular}

Tabel 3 menunjukkan bahwa rata-rata lama pemberian tablet zinc pada balita di Wilayah UPT Puskesmas Cinere Kota Depok yaitu selama 6.17 hari atau digenapkan menjadi 6 hari dengan minimal pemberian selama 1 hari dan maksimal pemberian selama 10 hari.

Tabel 4 Distribusi Rata-rata Durasi Diare di Wilayah UPT Puskesmas Cinere Kota Depok (n=75)

\begin{tabular}{lclcc}
\hline Variabel & Mean & SD & Min & Max \\
\hline Durasi & 2.86 & 1,31 & 1 & 7 \\
Diare & & & &
\end{tabular}

Sumber : Data peneliti 2020

Tabel 4 menunjukkan bahwa durasi diare rata rata pada balita di Wilayah UPT Puskesmas Cinere Kota Depok adalah selama 2,86 hari atau digenapkan menjadi 3 hari dengan minimal durasi diare 1 hari dan maksimal 7 hari.

\section{Analisa Bivariat}

Tabel 5 Hasil Analisa Statistik Hubungan Pemberian Tablet Zinc dengan Durasi Diare pada Balita di Wilayah UPT Puskesmas Cinere Kota Depok $(n=75)$

\begin{tabular}{cccc}
\hline \multirow{2}{*}{ Analisa } & \multicolumn{3}{c}{ Pemberian Tablet Zinc } \\
\cline { 2 - 4 } & r Spearman & P value & $\mathrm{n}$ \\
\hline Durasi & -0.255 & 0,027 & 75 \\
Diare & & & \\
\hline
\end{tabular}

Sumber : Data peneliti 2020

Tabel 5 menunjukkan hasil analisis rank Spearman untuk mengetahui hubungan antara pemberian tablet Zinc dengan durasi diare pada balita di Wilayah UPT Puskesmas Cinere Kota Depok. Nilai $\mathrm{p}$ value $=0,027$ yang berarti nilainya $<0,05$ sehingga dapat disimpulkan bahwa ada hubungan antara pemberian tablet Zinc dengan durasi diare pada balita di wilayah UPT Puskesmas Cinere Kota Depok. Hubungan pemberian tablet Zinc dengan durasi diare memiliki hubungan yang sangat lemah dan berpola negative dengan nilai koefisien korelasi spearman sebesar -0.255. Dapat disimpulkan bahwa semakin banyak ibu yang memberikan tablet Zinc pada balita diare dapat menurunkan tingkat durasi diare pada balita.

Hal ini juga sejalan dengan penelitian (Restuti \& Fitri, 2019) yang menujukkan adanya hubungan yang signifikan antara kejadian diare dengan tingkat asupan zinc dengan nilai $\mathrm{p}$ value $=$ 0.012. Pemberian tablet zinc dalam menangani diare pada anak usia 1 sampai 5 tahun efektif dalam pencegahan diare lebih lanjut (Ulfah, Rustina, \& Wanda, 2012). 
Penelitian Wahyuni \& Dermawan, (2018), menunjukkan bahwa hasil penelitian asupan seng dan vitamin A dengan kejadian diare pada balita sebanyak 9.3\% responden mengalami diare, kurang asupan seng sebanyak $13 \%$, dan kurang asupan vitamin A sebanyak $3.7 \%$, oleh sebab itu terdapat hubungan dengan $\mathrm{p}<0.05$.

Zinc berperan pada metabolisme yang berfungsi sebagai regenerasi jaringan yang berada di saluran cerna. Mekanisme memperbaiki penyerapan cairan dalam lumen usus dan dan dapat mengurangi frekuensi diare serta mempersingkat lama durasi diare (Latif, 2015).

Ditemukannya responden yang masih tidak patuh dalam pemberian tablet zinc pada anak diare juga sejalan dengan hasil penelitian dari Pujianti (2018), didapatkan bahwa kepatuhan responden dalam memberikan obat lebih dari 50 persen responden kurang disiplin, dikarenakan persepsi responden beranggapan bahwa aturan dalam meminum obat tersebut tidak begitu berpengaruh pada penyembuhan penyakit. Hal tersebut bersugesti bahwa tidak yakin jika akan sembuh dari diare hanya dengan mengikuti anjuran petugas kesehatan dalam pemakian obat dengan tuntas.

\section{SIMPULAN}

1. Gambaran karakteristik balita yang mengalami diare menunjukkan bahwa dari 75 responden rata-rata usia anak yaitu 23 bulan, mayoritas berjenis kelamin laki-laki yaitu sebanyak 44 responden $(58.7 \%)$.

2. Gambaran pemberian tablet zinc menunjukkan bawah dari 75 responden rata-rata memberikan tablet zinc selama 6 hari.

3. Gambaran durasi diare pada balita menunjukkan bahwa dari 75 responden rata-rata durasi diare pada balita selama 3 hari.

4. Hasil analisa menggunakan uji Uji kolerasi Rank Spearman menunjukkan bahwa terdapat hubungan antara pemberian tablet Zinc dengan durasi diare pada balita di wilayah UPT Puskesmas Cinere Kota Depok dengan nilai $p$ value $=0,027$ yang berarti nilainya $<0,05$.

\section{SARAN}

Penelitian ini disarankan lebih memotivasi dan mengedukasi orang tua yang memiliki anak balita yang sedang mengalami diare agar lebih patuh dalam memberikan terapi farmakologi tablet zinc dalam 10 hari berturut turut sesuai dengan dosis yang diberikan dan disarankan untuk melakukan pendampingan dalam pemberian tablet zinc agar lebih memperkuat hasil penelitian

Penelitian ini diharapkan dapat menambah referensi mengenai panatalaksanaan diare pada balita dan dapat dijadikan sebagai sumber acuan bagi penelitian selanjutnya.

Penelitian ini diharapkan orang tua khususnya ibu dapat memberikan tablet zinc kepada anak dengan anjuran dosis yang sesuai yaitu memberikan tablet zinc tanpa putus dalam 10 hari kepada anak balita yang mengalami diare.

\section{DAFTAR PUSTAKA}

Akbar, H. (2017). Faktor yang Berhubungan dengan Kejadian Diare pada Anak Balita di Kecamatan Sindue Kabupaten Donggala. Jurnal Kesehatan Masyarakat, 2(3), 78-83.

Anitasari, B., \& Sappe, J. (2019). Faktor yang Berhubungan dengan Lama Perawatan Pasien Diare. Jurnal Fenomena Kesehatan, 2(1), 258-268.

Dinas Kesehatan Kota Depok. (2019). PROFIL KESEHATAN KOTA DEPOK TAHUN 2018.

Huda, N., Perwitasari, D. A., \& Risdiana, I. (2017). Pengaruh Pemberian Kombinasi Probiotik dan Seng terhadap Frekuensi dan Durasi Diare pada Pasien Anak di Rumah Sakit PKU Muhammadiyah Yogyakarta. Indonesian Journal of Clinical Pharmacy, 6(1), 
11-21. https:/ / doi.org/10.15416/ijcp.2017.6.1.11

Illahi, R. K., P, F. F., \& Sadharta, S. (2016). Tingkat Pendidikan Ibu dan Penggunaan Oralit dan Zinc pada Penanganan Pertama Kasus Diare Anak Usia 1-5 Tahun: Sebuah Studi di Puskesmas Jati Malang. Pharmaceutical Journal of Indonesia, 2(1), 1-6.

Indriani, L., Fitriyanti, D., \& Azzikri, A. A. (2019). Penilaian Rasionalitas Pengobatan Diare pada Balita di Puskesmas Bogor Utara Tahun 2016. Fitofarmaka, 9(1), 9-15. https://doi.org/.1037//0033-2909.126.1.78

Kemenkes RI. (2011). Situasi Diare di Indonesia. Jakarta: Bakti Husada.

Kemenkes RI. (2018). Hasil Utama Riset Kesehatan Dasar (RISKESDAS). Journal of Physics A: Mathematical and Theoretical, 44(8), 1-200. https://doi.org/10.1088/1751$8113 / 44 / 8 / 085201$

kementrian pemberdayaan perempuan dan perlindungan anak. (2018). Profil Anak Indonesia. In Ilmu Pendidikan (Vol. 5).

Latif, H. A. (2015). Terapi Suplementasi Zink dan Probiotik pada Pasien Diare. J Agromed Unila, 2(4), 440-445.

Pujianti, N. (2018). Hubungan Pengetahuan dan Komunikasi dengan Kepatuhan Penggunaan Oralit dan Zinc Saat Diare di Daerah Pinggiran Sungai. Jurnal Publikasi Kesehatan Masyarakat Indonesia, 5(3), 98-102.

Restuti, A. N. S., \& Fitri, Y. A. (2019). Hubungan antara Tingkat Asupan Vitamin A, Zinc, dan Polyunsaturated Fatty Acid (PUFA) dengan Kejadian Diare Balita. Indonesian Journal of Human Nutrition, 6(1), 32-40. https:/ / doi.org/http:/ / dx.doi.org/10.21776/ub.ijhn.2019.006.01.4

Riskiyah. (2017). Peranan Zinc pada Penanganan Kasus Penyakit Diare yang Dialami Bayi Maupun Balita. Journal of Islamic Medicine, 1(1), 22-29. https:/ / doi.org/10.1017/CBO9781107415324.004

Ulfah, M., Rustina, Y., \& Wanda, D. (2012). Zink Efektif Mengatasi Diare Akut Pada Balita. Jurnal Keperawatan Indonesia, 15(2), 137-144.

Wahyuni, E., \& Dermawan, S. (2018). Hubungan Asupan Seng dan Vitamin A Dengan Kejadian Diare Pada Anak Umur 1-5 Tahun. Holistik Jurnal Kesehatan, 12(3), 136-145.

Wijayanti, A. I. P., \& Astuti, W. T. (2019). Pemberian Pendidikan Kesehatan Terapi Zink untuk Mengurangi Frekuensi Diare. Jurnal Keperawatan Karya Bhakti, 5(1), 7-13. https:/ / doi.org/10.1017/CBO9781107415324.004 